\title{
What's Different About Emerging Markets, and What Does it Mean for Theory and Practice?
}

\author{
John Roberts ${ }^{1} \cdot$ Ujwal Kayande $^{2} \cdot$ Rajendra K. Srivastava $^{3}$ \\ Published online: 13 October 2015 \\ (C) The Author(s) 2015. This article is published with open access at Springerlink.com
}

Much has been written about emerging markets, especially since the term "BRIC" was coined in by Jim O'Neill [13], then-chairman of Goldman Sachs Asset Management, in his publication Building Better Global Economic BRICs. However, very often, these perspectives have been based on anecdotal observations followed by implications for economic policy and management actions that have not been appropriately investigated. Limited attention is devoted to theoretical underpinnings, corresponding frameworks, and empirical analyses. Additionally, the fact that there is often very little in common between Brazil, Russia, India, and China (and now South Africa) is lost. At the same time, many countries with strong similarities to each of them are correspondingly ignored.

Over the past decade, many marketing academics have examined the marketing implications of the differences between emerging markets (EMs) and developed markets (DMs), as well as the market phenomena across and within EMs. Some work is conceptual and provides excellent frameworks (e.g., $[2,5,10,18]$ ), other studies are empirical (examples include papers in the International Journal of Research in Marketing's 2013 Special Issue on Emerging Markets; [6, 12, 17]) . This Special Issue of Customer Needs and Solutions builds upon the increasing academic and managerial interest

John Roberts

johnr@agsm.edu.au

1 UNSW School of Business, The University of New South Wales, Sydney, NSW 2052, Australia

2 Melbourne Business School, 200 Leicester Street, Carlton, VIC 3053, Australia

3 Singapore Management University, 81 Victoria Street, Singapore, Singapore in identifying the marketing theory and practice implications of the seismic shifts in the current world economy. In this editorial, we focus on summarizing some of the findings of the papers in this Issue. Additionally, we lay out a framework for future analyses.

So, what, if anything, is different about emerging markets that really matters? We have summarized nine broad areas in which the differences between emerging and developed markets have significant theoretical and managerial implications (outlined in Table 1).

Before addressing EMs, it is useful to understand the historical context from which they evolved. Emerging markets and their role in the global economy form a natural development in the dynamics of international trade. Ricardo, with his theory of comparative advantage in 1817 [3] noted that because different markets had different resources, wealth could be created by countries specializing in those industries in which they had a relative advantage (for example, with the British making cloth and the Portuguese making wine). The success of early European traders applying these principles led to colonization where terms of trade could be underpinned by military power; with the Indian Mutiny, Boxer Rebellion in China and opening of Japanese markets by Admiral Perry providing excellent examples [8]. Economic history up to the beginning of the twentieth century focused on trade as a source of raw materials (reflecting a supply side view of the world and the primacy of western markets). There was little focus on foreign markets and that which there was, was seen as a way of absorbing excess capacity and leveraging the colonists' ability as an intermediary (e.g., Boston Tea Party, Salt March on India). This situation continued until the Second World War (1939-1945), after which many of what were then called developing countries gained their independence. However, with the fall of colonialism, under-developed markets were still seen as terms of trade takers, albeit with limited 
Table 1 Differences between EMs and DMs that have significant marketing theory and practice implications

Issue

Theoretical implications

Practice implications

1 Diversity and fragmentation of markets (consumers) across markets

- Differences in price sensitivity of customers and affordability of options (including channels) to market segments

- Market specialization to offset market inefficiencies

2 Diversity \& segmentation within market

- Assumptions from DMs do not transfer to EMs-information costs higher, affordability lower, etc. in EMs

- Room for market specialists in EMs

- Harder to assume away market friction (e.g., information transparency) and complexity (e.g., game theoretic solutions based on information transparency and economically rational, profit maximizing behavior)

- Many segments and hence forms of differentiation (quality, package sizes, prices)

- Managing across borders - multiple business models across countries

- Differences in tier 1 and tier 3 city customers in product-market life cycle (PMLC) knowledge and brand preferences imply multiple business models and focus on expertise regarding managing within borders

- Market mix management at the (product $x$ market segment) cell level-manage complexity versus payoff

- Bundling and then unbundling customer solutions (as markets become better educated)

- Developed market MNCs need to partner with locals to overcome information costs and ability to deal with regulators and to navigate distribution channels

3 Differences in market growth rate across segments (e.g., urban vs rural; Tier 1 and 2 Cities)

- Unequal distribution of wealth imply middle class growth rate higher than GDP

- Market growth rate in urban areas faster than country average

4 Stage of Product-Market Life Cycle (PMLC)

- Different stages of PLC for same product in different regions may require "pull" strategies in growth markets and "push" in mature ones and the

- Market growth rates by segment and product category

- Reflected in growth in demand for FMCG as well as durables transition path between the two.

5 Changing intensity of competition

- EMs are perfect for testing market evolution and market dynamics theories e.g., - Intensity of competition likely to be higher in EMs (DMs markets have brand development, concentration of like-stores in same geographical area to "consolidated") enable comparisons

- Important to think of, and act consistently with, the notion of "product-market life cycle" (PMLC) to develop strategies by product and location.

- Market growth attracts an increase in competitive milieu in EMs implying need to move quickly (time-based competition)

6 Evolution of institutions and eco-systems and leap-frogging in the absence of resistance from legacy systems

- Evolution of institutions (e.g., channels; organized retailing); kirana stores

- Value of localization (Alibaba and FlipKart faster than Amazon); complimentary to Big Bazaar and Reliance etc.; growth of e-tailing (Flipkart • New institutions and channels aided by limited/no organized retailing or legacy \& Alibaba)

- Technological leap-frogging no competitive legacy systems (e.g., Telco'sChina, India, Thailand, digital banking)

- Retail leap-frogging (Alibaba and FlipKart vs Amazon) systems as competitors

- Emerging market MNC's can learn from the West

- With patent expiration in DMs, EM companies can focus on product simplifications \& process innovations to try to secure competitive advantage

- Greater focus on "exploitation" of innovations in emerging markets with a focus on global supply chain (i.e., process rather than product) innovations

7 Branding opportunities \& implications

Consumers less informed implies:

- Brands are still aspirational

- Rejection of "cheap" options-Tata Nano; Chinese consumers shopping for luxury items

- Easier to develop brands in EMs, but time is of essence as competitors likely to jump in due to market attractiveness

- May be stronger for private labels-control of shelf space and ability to learn from the evolution in the west ("branded" private labels?)

- Higher motivation for EM companies to invest in brands and new channels

8 Marketing investments-growth \& risk implications

- Growth rate (and opportunity) higher in EMs; unequal distribution of new wealth; the risk of not taking risks

- Emerging market brands will seek acceptance in developed markets (e.g., Chinese cosmetic brands seeking recognition in France)

- Shift from B2B marketing to developed markets to B2C marketing to build market share in area

- Attempt by EM companies to climb the value ladder thru development of purchase of global brands (and associated distribution systems, technologies etc.)

- Development of, and shift in share, to globally branded private labels (linked to supply chain giants such as Li \& Fung)

- Short-term risk may be higher in EMs but long-term risk lower-greater risk in not taking the risk to compete in EMs.

- Developed market MNC's underinvesting (glass half empty)-emerging market MNC's-more patient capital (glass half full) \& investing in EMs to win

9 Beyond emerging markets-catching the next wave: pre-emerging markets (PEMs)

- Firms and government institutions from EMs are investing heavily in undeveloped markets. Infrastructure is improving in those markets and a small middle class is being created.

- To the extent that first mover advantages pertain in undeveloped markets through the creation of market based assets in them, MNCs from DMs may find it difficult to penetrate those markets that are not yet in growth, if they do, indeed, take off. 
abilities to absorb non-essential goods from industrialized nations because of low per capita incomes.

The unfolding independence of Europe's erstwhile empires saw initial growth in post-colonial economies with the rise of the Asian tigers, consisting of Hong Kong, Korea, Singapore and Taiwan [14]. As these and other countries moved to higher value-added industries in terms of supply, the workforce become more affluent, and multiplier effects kicked in, leading to a prosperous, numerous, and fast growing middle class in many Asian economies. This corresponded with market saturation in many Western markets (following World War II shortages being filled) and a growing orthodoxy of the benefits of free trade. That is, not only did the supply advantages of what were then called developing markets become obvious in terms of cheap and highly trainable labor, the demand potential became important to the earnings of multinational corporations. That led inevitably to a study of the idiosyncrasies of these markets, now somewhat more politically correctly termed "Emerging Markets." This growth in prosperity in a select few Asian markets has now spread through much of Asia, and many see Africa as the next frontier in terms of high economic growth. A good example of research in this area is C. K. Prahalad's [16] "Bottom of the Pyramid" research stream of the new business models possible in emerging markets and their potential reverse impact on the West. We stand poised in a position where EMs have overtaken DMs in terms of economic activity, as illustrated in Fig. 1, taken from Gibley [4]. And yet, the research that EMs have attracted in our literature is a microcosm relative to that devoted to DMs. This Special Issue aims to provide one small set of thoughts and studies to address that imbalance.

In our understanding of the general characteristics of emerging markets, the first and foremost issue is the diversity and fragmentation across them. While there may be differences in consumer needs and solutions across developed markets, say between New York City and Salt Lake City, or between the USA and Germany, these differences pale in comparison to those between customer resources, preferences, and behaviors in EMs across Manila, Mombasa, Mumbai, and Moscow-or between Bangladesh and China. These differences span almost every metric compiled by the United $\mathrm{Na}$ tions-education, income, religion, literacy, market access, currency, government and regulation, infrastructure and logistics, availability of technology, resources and the like. Understanding these multi-faceted differences and their implications via multi-disciplinary approaches is critical, as espoused by Sudhir et al. in this issue.

Managing within and across EM borders provides both challenges and opportunities. Indeed, how one manages across borders represents a major theme of research inquiry for EMs. Companies spanning these markets must accommodate multiple business models to manage differences cited above. These business models must in turn address differences in market segments, price sensitivities and product affordability, market access and logistics, as well as their dynamics.

Theories developed in the developed west based on market efficiency may not work in the face of seemingly inefficient localized markets. For example, while firms might focus on core competencies in the developed west (the investor can put together their own "portfolio" of opportunities as they can buy shares across corporate securities), we very often see familymanaged conglomerates in EMs that are co-dependent on resources and market-links.

It is important to understand how consumers behave across markets, as microeconomic behaviors impact macroeconomic metrics. For example, China's one-child policy fosters saving behavior in the absence of a social safety net, as well as a reliance on foreign exports. The Indian economy, on the other hand, is less reliant on exports and more on internal consumption. In this issue, Chandy and Narasimhan note that EMs are increasingly important in terms of global consumption and sources of growth, and identify the challenges and opportunities that are associated with them. Besides providing manufacturers with the opportunity to develop new solutions, the diversity and novel characteristics of emerging markets make them particularly rewarding places in which to apply the
Fig. 1 Relative size of developed and emerging markets over time. $P P P$ purchasing power parity (used with permission from [4])

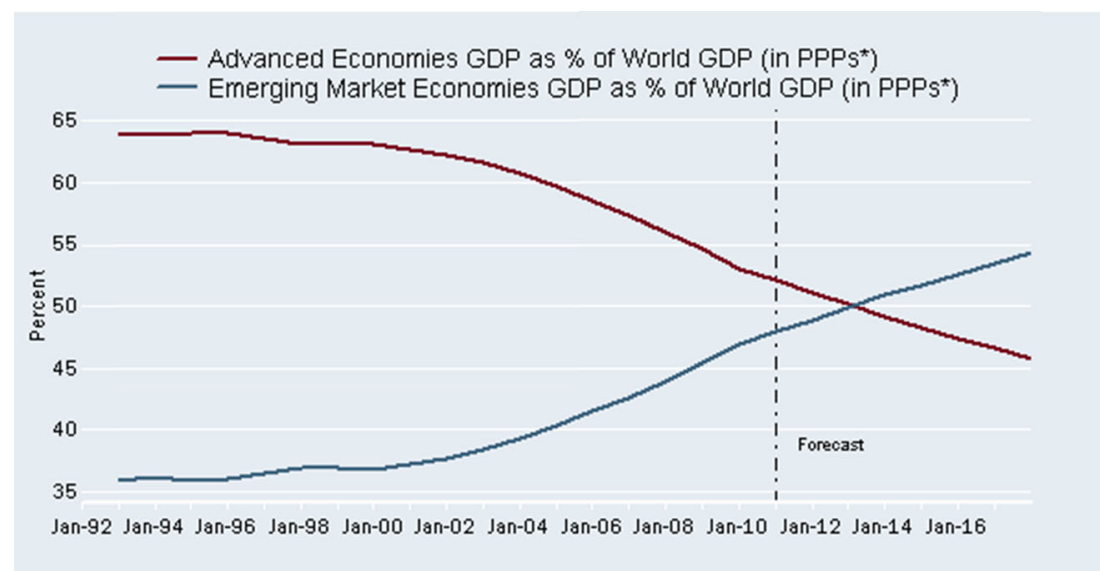


burgeoning concept of user-based innovation (see Venugopal and Viswanathan in this issue). Differences in evaluation processes across consumers lead naturally to a consideration of how product and service opportunities present themselves (illustrated by Kamakura and Mazzon in this issue).

We must also examine the implications of diversity and segmentation within EMs. Different regions within the same country (e.g., Tier 1 versus Tier 2 cities; rural versus urban areas; states and provinces under different administrations) are at different stages of development. Country comparisons may often be less relevant. While China is more homogeneous than India when it comes to language and culture, urban (especially coastal) China has developed to a much greater extent than inland, rural areas. Eckhardt and Wang (in this issue) argue that we need different models to understand regional differences, both from a supply side and from a demand one.

Not only is the present heterogeneous within different EMs, so too is the future. There are significant differences in growth rates and opportunities within countries. Singapore with its mostly urban, high income population compares very favorably with the Philippines. But, with the country's GDP growing at 7-8 percent and urban areas growing at $15 \%$, might the Manila CDB soon pose a challenge to Singapore which has no hinterland to support its growth? Similarly, while India is woefully poor on a per capita basis, its emerging middle class provides market opportunities and affluent clienteles far larger than many European countries. While India as a whole presents business challenges, opportunities are easier for firms to avail themselves of in progressive states such as Gujarat and Andhra Pradesh. As a result, within market (country) differences require targeted strategies which can be facilitated by business analytics-the application of which may, ironically, have higher payoffs in emerging than developed markets.

An important realization is that the same product can be in different stages of the product life cycle in different countries, as well as within. For example, market penetration levels for home appliances vary significantly across emerging markets ranging from very low (e.g., India) to close to market saturation (e.g., Turkey). This has important implications for the marketing mix which should transition from "pull" to "push" strategies as markets change from embryonic, to growth, and to maturity stages. It suggests that companies should focus on country-specific product-market life cycles (or even finer) rather than global product life cycles.

Growth opportunities in EMs suggest that competitive intensity is likely to increase. This has several implications. First, while these markets are risky, the greater risk lies in not taking the risk of participating in them because (a) resources generated by firms successful in these markets are likely to be deployed by local players for growth in DMs (e.g., Huawei, Bharti Airtel), and (b) late entry into EMs will result in loss of opportunities. Emerging markets provide a natural crucible for research in the evolution of time-based competition. This is an area where research is needed, but is scarce in terms of recent empirical market inquiries.

Amidst all the changes reflected in growing consumer literacy, economic resources, and disposable income, one must anticipate the evolution of institutions and eco-systems. This is well illustrated by the collaborative roles of "kirana" (mom and pop) stores with organized retailing (see Sinha, Gokhale, and Rawal in this issue), operating in parallel with e-tailing. This powerful combination of bricks and clicks is enabling distributors to integrate both forward (via kirana stores) and backwards (through private labels). In this context of Indian supermarket retailing, Narayan et al. [12] found that upper and lower middle-class shoppers tend to patronize modern supermarkets, while "modal" middle-class shoppers favor kirana stores. Given the differences in the size of these segments, this finding of differential patronage has significant implications for market entry, as well as defensive strategies for kirana stores.

While emerging markets suffer from a number of disadvantages in terms of being late movers in many products and categories, there are also many places where they have advantages, particularly because they are unencumbered by aging legacy assets. One obvious example is in the telecommunications industry where the lack of extensive copper land line networks has freed emerging economies to focus on mobile solutions. The renewable (solar, wind) energy sectors represents a second example of how emerging markets have developed an advantage by not being held back by legacy assets.

Emerging markets provide a great laboratory to study impact of branding activities on competitive positions and business performance. While brands are under pressure in DMs, EMs provide brand-growth opportunities. Historically, EM companies have been upstream outsourcing partners to global MNCs, enjoying only modest margins. They now see the opportunity to capture greater value as they shift from business-to-business (B2B) sales to business-to-consumer (B2C) branding and marketing (e.g., see [10]). The rapid growth of organized retailing also provides opportunities for the development of branded private labels as EM retailers are learning quickly from the experiences of their DM counterparts.

From the viewpoint of growth and risk management, one must make some key observations. Global market leaders will have no option but to play in EMs. This imperative stems from a number of factors. Growth objectives and the need for scale is a large one. A requirement for defense in home markets also leads to the necessity of positioning against both local MNC and EM players (with the accompanying advantages that they bring). The need to balance the firm's portfolio with respect to earnings, resource requirements, and volatility suggest that EMs present a useful form of reducing otherwise undiversifiable risk. The paper by Vila, Bharadwaj and 
Bahadir in this issue focuses on exploration and exploitation oriented marketing strategies to foster sales growth in emerging markets, thus moving from the research issues associated with emerging markets to the managerial issues that applying this work entails.

While EMs are risky and volatile, the greater (long-term) risk lies in not taking the risk. Those emerging market firms who succeed on their own and other EMs will do so against intense competition-and this will make them formidable opponents when they expand into DMs. It is important to note that while incumbents see the glass as half empty, EM giants approach global opportunities with a more patient (often government assisted or family backed) capital and perceive the glass as half full. They are more likely to invest for the longrun. This may spell trouble for those conservative, developed market global leaders that try to ring-fence their existing, currently comfortable, DM earnings streams.

To summarize, we would say that we must understand the different characteristics of EMs, especially when approached with the mindset of managers trained in DMs and for organizations run out of DMs. However, we have spelt out the dangers of tarring all EMs with the same brush (or even all regions with a single EM with the same brush). The fact that these different product markets are developing at different rates, and with different patterns, is likely to exacerbate the risks in approaching these markets in the same way. It suggests that EMs might even provide a major source of reverse innovation flows with DMs. For example, Jensen [7] shows how mobile phones can revolutionize markets. Mobile banking apps in Kenya with M-PESA and agricultural apps in China with China Mobile have now led to a far greater variety of mobile applications in DMs. Perhaps more importantly, this diversity in EM market environments may raise the question as the degree to which it is even meaningful, insightful, and useful to talk about "EMs" as a single grouping. This very question was recently addressed by an excellent series in the UK Financial Times $[11,20]$. Solutions suggested included a matrix structure based on economic base (resource versus manufacturing) and current account balance (surplus versus deficit) [15], governance regime segmentation (particularly with respect to capital markets [19]), and classification by risk Kozhemikin [9]. However, all of these frameworks have the disadvantage that they start with the EMs, rather than starting with the objective of why we are studying EMs in the first place. Starting with the reason for analysis (that is, understanding the decisions that will be based on our analyses) will simplify our task dramatically and push us a lot further out on the parsimonydepth of insight efficient frontier.

EMs are important to global actors, be they in DMs or EMs, because EMs represent a large proportion of the earnings of many of these global firms. More importantly, EMs represent a much larger proportion of where most firms' growth will come from. However, a focus on EMs should not divert us from a new potential source of earnings growth, those markets that are yet to start emerging (Pre-emerging Markets or PEMs). It is telling that India and China (the two largest EMs) are investing heavily in Africa, potentially preempting growth opportunities of DM firms that wait to see stronger signals of growth before committing significant resources. A 2012 McKinsey study found that firms headquartered in EMs have a $13 \%$ growth rate advantage over those headquartered in DMs, and that most of that advantage comes from a greater reinvestment of earnings into their businesses while paying lower dividends, allocating resources more dynamically to markets that are likely to grow, and an intense focus on markets that are lower cost, higher growth, and larger [1]. Many of these markets are PEMs. At the same time, DM firms tend to invest in markets that are smaller, higher margin, and more mature, reflecting their lack of appetite for risk.

One significant aspect of EMs and PEMs is that they are typically characterized by the presence of a sizable subsistence marketplace. Such subsistence marketplaces provide an exceptional avenue for innovation, the study of which is an exciting area of research in marketing. Venugopal and Viswanathan (in this issue) provide us with a sense of what is possible, and indeed a pathway for future research in this important area, wonderfully rounding out this Special Issue.

Open Access This article is distributed under the terms of the Creative Commons Attribution 4.0 International License (http://creativecommons.org/licenses/by/4.0/), which permits unrestricted use, distribution, and reproduction in any medium, provided you give appropriate credit to the original author(s) and the source, provide a link to the Creative Commons license, and indicate if changes were made.

\section{References}

1. Atsmon Y, Kloss M, and Smit S (2012) Parsing the growth advantage of emerging market companies. McKinsey Quarterly, https:// www.mckinseyquarterly.com/PDFDownload.aspx?ar=2969

2. Burgess SM, Steenkamp JBEM (2006) Marketing renaissance: How research in emerging markets advances marketing science and practice. Int J Res Mark 23:337-356

3. Dornbusch R, Fischer S, Samuelson PA (1977) Comparative advantage, trade, and payments in a Ricardian model with a continuum of goods. Am Econ Rev 67:823-839

4. Gibley M (2012) "Emerging markets: what you should know" Charles Schwab expert insights and commentary http://www. schwab.com/public/schwab/nn/articles/Emerging-Markets-WhatYou-Should-Know (Accessed 29 Sep 2015)

5. Grewal R, Lilien GL, Bharadwaj S, Jindal P, Kayande U, Lusch RF, Mantrala M et al (2015) Business-to-business buying: challenges and opportunities. Cust Needs Solutions 2(3):193-208

6. Gu FF, Hung K, Tse DK (2008) When does guanxi matter? Issues of capitalization and its dark sides. J Mark 72(4):12-28 
7. Jensen R (2007) The digital provide: information (technology), market performance, and welfare in the South Indian fisheries sector. Q J Econ 122:879-924

8. Kiernan V G (1982) European empires from conquest to collapse, 1815-1960. 4. Fontana Paperbacks

9. Kozhemikin A (2015) "Redefining EM: asteriscs, new acronym for emerging markets" Financ Times

10. Kumar N and Steenkamp JBEM (2013) Brand breakout, Palgrave Macmillan ISBN 9781137276612

11. Kynge J and Jonathan W (2015) "Emerging markets: redrawing the world map" Financ Times

12. Narayan V, Vithala R, Sudhir K (2015) Early adoption of modern grocery retail in an emerging market: evidence from India. Market Sci. doi:10.1287/mksc.2015.0940

13. O’Neill J (2001) Building better global economic BRICs. Goldman-Sachs: Global Investment Research
14. Page J (1994) The East Asian miracle: four lessons for development policy. NBER macroeconomics annual 1994. The MIT Press, Cambridge

15. Power M (2015) "Redefining EM: matrix offers new perspective on definition". Financ. Times

16. Prahalad CK (2005) The fortune at the bottom of the pyramid: eradicating poverty through profits. Wharton School Publishing, Upper Saddle River

17. Sheng S, Zhou KZ, Li JJ (2011) The effects of business and political ties on firm performance: evidence from China. J Mark 75(1):1-15

18. Sheth JN (2011) Impact of emerging markets on marketing: rethinking existing perspectives and practices. J Mark 75:166-182

19. Smith J P (2015) "Redefining EM: governance regimes are the key distinction". Financ Times

20. Wheatley J (2015) “Q \& A: what is an emerging market?" Financ Times 